\title{
STUDIES ON PHENOTYPIC VARIATION IN MANIOLA JURTINA (LEPIDOPTERA : SATYRIDAE) IN THE WYRE FOREST, ENGLAND
}

\author{
OWEN TUDOR* and DAVID T. PARKIN \\ * West Bromwich College of Commerce and Technology, Kendrick Street, Wednesbury SW10 9ER; \\ and + Department of Genetics, University of Nottingham, University Park, Nottingham NG7 2RD
}

\begin{abstract}
Summary
Individual adult butterflies of the species Maniola jurtina vary in the number of subterminal spots on the undersurface of the hind-wing. The incidence of this spotting differs between the sexes, males usually having more spots than the females. The character shows a variable heritability, depending upon sex and temperature. Two adjacent populations were studied in Worcestershire between 1970 and 1974. Individuals were caught and marked, their spot number, size and subsequent capture were recorded. There is no difference in the occurrence of the various spot categories between the sites, nor within a single season. The incidence of two-spotted males and unspotted females declined over the 5 years. Higher-spotted individuals showed corresponding increases in both sexes. Differences in survival have been found between the spot classes that could explain these changes. It is argued that the heritabilities are low, and that caution is necessary in interpreting the phenotypic changes as due to selection.
\end{abstract}

\section{INTRODUCTION}

Maniola jurtina, the Meadow Brown butterfly, rose to prominence during the dispute over the relative importance of natural selection and random genetic drift to evolutionary change in nature. It exhibits variation in the number of subterminal spots around the margin of the undersurface of the hind-wings. This character was used by E. B. Ford and his colleagues at Oxford University as a means of comparing populations and detecting changes within them. It is easy to score under field conditions, and yet affects the appearance of the individual rather little, certainly much less than melanism in moths. Its study has allowed an analysis of the influences of the physical and biological environment upon the manifestation of an apparently trivial "polygenic" character.

The earlier studies on spot number in this species have been extensively reviewed by Ford (1975). They fall into three broad sections. The first consists of a series of studies on the mainland of Britain, supplemented by work in Europe, and in some instances extending over several years. The second section pertains to the ecological genetics of the species in the Isles of Scilly, off south-western Britain. The third set of studies is more experimental. It includes the assessment of spot heritability, the effects of predation and parasitism, and some analyses of mortality of wild-caught material.

The number of spots on the hind-wing varies from zero to six, although six spots is exceedingly rare, and both wings usually have the same number. It behaves as a genetic character with a heritability at a rearing temperature 
of $15^{\circ} \mathrm{C}$ of 14 per cent in the males and 64 per cent in the females (McWhirter, 1969). Ford (1975) reports that higher values of 47 per cent and 78 per cent were obtained at $22^{\circ} \mathrm{C}$.

Not only do the sexes differ in their heritabilities, but they also have different spot distributions. In almost all populations, the majority of males are two-spotted. Females vary from region to region, but usually the commonest form has no spots. However, in south-west Britain, two-spotted females are almost equally common, and the distribution becomes bi-modal. There is a more or less sharp boundary between the "unspotted" and " bimodal" populations, which appears to move in geographical position from year to year.

In the populations inhabiting the Isles of Scilly, the males are almost always unimodal at two spots, but the females show marked, and rather consistent, differences. The larger islands tend to have equal numbers of females with zero, one and two spots, whereas smaller islands are more variable. Ford and his colleagues have concluded that their observations can only be explained by invoking natural selection. The agents of this selection are not fully understood, but Ford suggests that, in some areas at least, populations can change with " ease and rapidity" to new patterns of spot-distribution, presumably responding to changes in the biological or genetic environment. In one study (McWhirter and Greed, 1971) the position of the spots was analysed in addition to the number. Consistent trends occur in the distribution of the various spot-positions, which require further analysis, both genetic and ecological.

The study of Maniola jurtina is deficient in long-term studies of single populations. Dowdeswell (1961) reports a 5-year study of a population near Andover in Hampshire. He finds evidence here of differences in spot number with season, perhaps reflecting differences in emergence pattern. However, his numbers are too small for detailed statistical analysis.

One of us (O. T.) has undertaken an intensive study of butterfly behaviour in wild populations from the Wyre Forest in Worcestershire. This was begun in 1970 and has continued with only brief interruptions until the present day. Part of the work involved the marking and recapturing of several species, including $M$. jurtina. The present paper, which is the first of a series, reports upon aspects of the research that are pertinent to the ecological genetics of Maniola.

\section{Methods}

Maniola jurtina has a single generation in a year, and the adult flies from mid-June onwards, often until early September. This protracted flying period seems to reflect a very variable larval growth rate (Ford, 1975). The food plants of the larvae are grasses, particularly Poa pratense, and the species is especially abundant in rough, uncut grassland.

The populations that we have studied are from the Wyre Forest in the western midlands of Britain. No previous scientific survey had been made of $M$. jurtina in this region. The area of study is shown in fig. 1 , and includes three contiguous locations. Site 1 has been the principal area of study. It consists of the uncultivated margin of a larch plantation surrounded on all sides by woodland. A road runs along the northern edge, and its verges and hedges are included. The vegetation is varied, and typical of ungrazed 
land in the region. It is cut once a year, usually in August, but is otherwise undisturbed. Site 2 comprises a rough meadow that is cut regularly, and used as sheep grazing from time to time. This area is subject to human disturbance on occasion as a camping site. Site 4 is a narrow hill lane connecting sites 1 and 2 . It is bounded on the north by a coniferous plantation, and on the south by natural mixed woodland. Both of these woodlands were searched regularly, but only the latter yielded $M$. jurtina, and that only rarely.

The study area was visited regularly during the flight period of $M$. jurtina. The actual number of visits to sites 1,2 and 4 in the 5 years of the study is shown in table 1. The pattern of visits was similar in each year. As far as possible the same route was followed, as shown in fig. 1, and the entire area

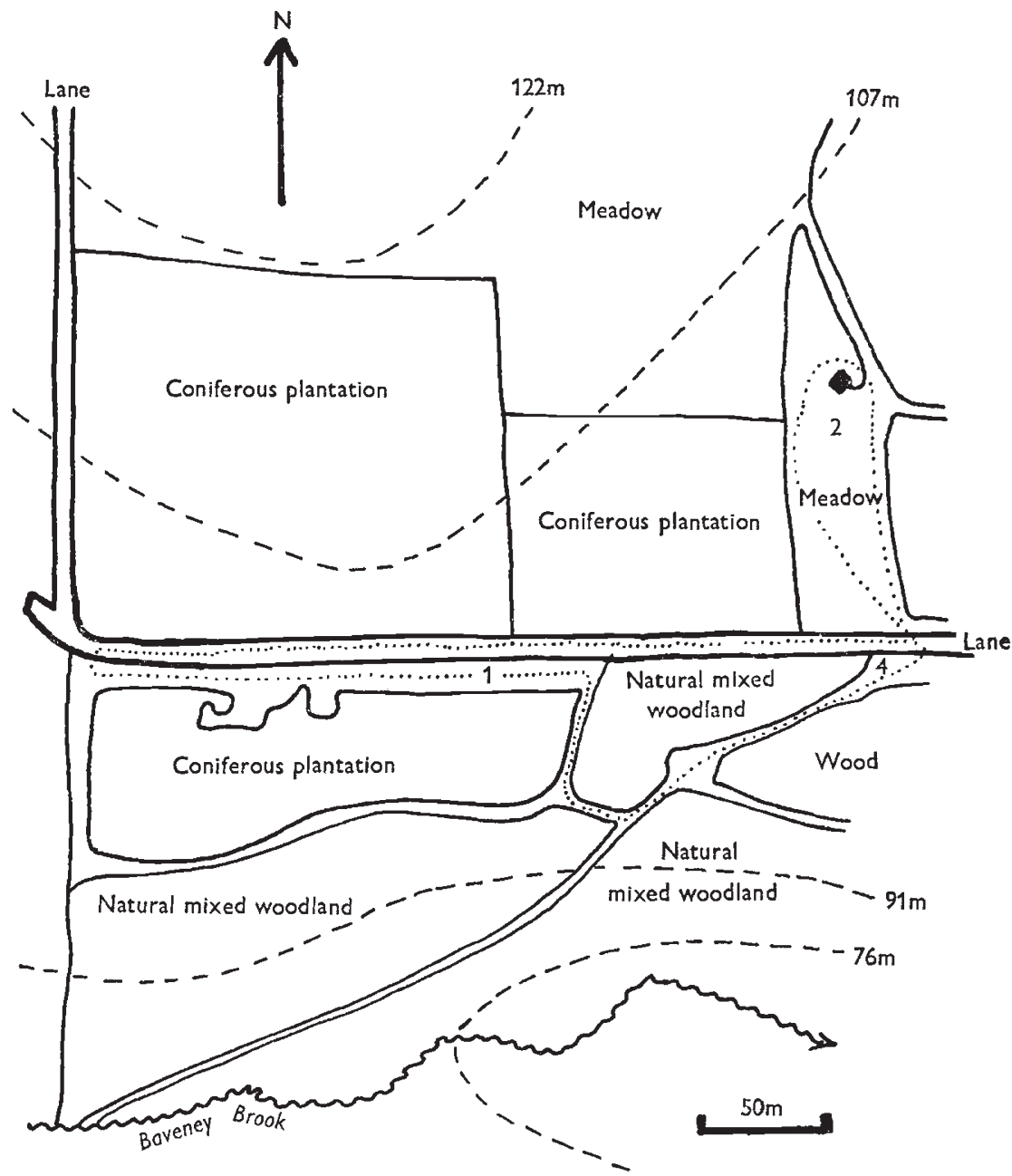

Fig. 1.-Map of the study area showing the disposition of Site 1 (rough grassland), Site 2 (meadow) and Site 4 (hedge bordered lane and woodland path); path of observer). 
was covered during a visit, so that, as far as possible, each butterfly had an equal chance of being captured. The time spent at each site was approximately the same on every visit. Occasional special visits were made expressly to catch and mark as many butterflies as possible.

TABLE 1

Number of visits to the sites in the study area during the flight period of M. jurtina

$\begin{array}{llccc} & \text { Flight period } & \text { Site } 1 & \text { Site } 2 & \text { Site } 4 \\ 1970 & \text { 13.VI-29.VIII } & 34 & 15 & 0 \\ 1971 & \text { 30.VI- 5.IX } & 24 & 17 & 22 \\ 1972 & \text { 29.VI- 3.IX } & 31 & 26 & 27 \\ 1973 & \text { 16.VI-28.VIII } & 32 & 25 & 28 \\ 1974 & \text { 15.VI-21.VIII } & 31 & 25 & 28\end{array}$

Individual butterflies were captured by net, and released as soon as possible. They were not pursued as this would $(a)$ result in their being driven from their chosen position, and $(b)$ damage the habitat. During 1970, individuals were marked with a colour code related to the date of capture. The marks were made with quick-drying cellulose paint applied to the underside of the basal area of the hind-wing. This was discontinued after 1970 since there was only a limited range of colours available. Furthermore, multiple capture resulted in a large number of marks on some individuals (e.g. one specimen with 15 !).

During the early summer of 1971 , various marking procedures were tried on the species. The most satisfactory technique seemed to be the application of a number in the same area of the wing as before, using marking ink applied with a piece of sharpened plastic. The numbers were sufficiently small as not to be readily visible in the field, thus obviating selective bias in recaptures. Two colours of ink (yellow and white) were used to increase the number of marks.

On initial capture, the following data were recorded: (i) the time and date of capture; (ii) sex; (iii) the length of the left fore-wing from base to apex, if it was undamaged; (iv) the number of spots on the undersurface of each hind-wing. This sometimes differed between wings, and in such cases the left hind-wing has been recorded in this paper. On subsequent capture, the time, date, spot number and reference number were recorded. It was sometimes found that the number of spots declined from one capture to the next. It seems that the character is subject to phenotypic modification (i.e. it gets rubbed off), and this may affect some results. Butterflies that are old when they are first caught may have already lost a spot or two. However, very few of our animals were old and worn on first capture, and so spot-loss is unlikely to be a significant factor. It will be discussed at length in a future publication.

\section{RESUlts}

\section{(i) Population parameters}

We have complete mark-recapture data for the years from 1971 to 1974 from Site 1, over the whole flight period, and the results from these years are sufficiently complete that we have a choice of methods. Early studies of the 
population dynamics of Maniola jurtina (e.g. Dowdeswell et al., 1957) have used the techniques developed by Fisher and Ford (1947). They assume that the unit survival rate remains constant over the period of study, and because this may not be true, we have used the technique described by Jolly (1963, 1965).

Jolly's method enables us to calculate the survival rates from one sampling date to the next in each year for the two sexes separately. In order to convert these figures to daily survival rates, we have taken the $n$th root of the calculated rate, where $n$ is the number of days between captures. The results are too extensive to report here, but analysis of variance (table 2) shows that there is no difference in daily survival between the sexes $(P>0 \cdot 1)$, nor between years $(P>0.1)$. There is, however, evidence of a decrease in survival with advancing date in both males and females $(P<0 \cdot 01)$. This

TABLE 2

Analysis of variance of daily survival rate of Maniola jurtina in the years 1971 to 1974

\begin{tabular}{lcrccc}
\multicolumn{1}{c}{ Component } & Sum of squares & DF & Mean square & F & P \\
Year & 0.034 & 1 & 0.034 & 0.7 & $>0.5$ \\
Sex & 0.017 & 1 & 0.017 & 0.4 & $>0.5$ \\
Date & 0.339 & 1 & 0.339 & 7.3 & $<0.01$ \\
Interactions & 0.124 & 4 & 0.031 & 0.7 & $>0.5$ \\
Residual & 7.169 & 155 & 0.046 & - & -
\end{tabular}

could be due to an increasing age-structure later in the season. However, we think that it is not, for there are differences in the probability of recapture of newly emerged butterflies early and late in the season. Males that emerge in the first half of the season are approximately twice as likely to be recaptured as those emerging later. This is clearly significant $(\mathrm{P}<0.001)$, and supports the two-fold difference in computed survival rate. The data for females are less conclusive, partly because they emerge somewhat after the males, and so less time is available for their recapture. The relationship between survivorship and date is: survival $=0.8539-0.00297 \times$ day. Thus, an animal that appears early in the season, in late June or early July, will probably survive for about 4 or 5 days. An individual that emerges 6 weeks later in mid-August can only expect to live for 2 to 3 days.

The population of $M$. jurtina that we have studied is rather small, and short-lived. Consequently the recapture data are rather few, and there are striking, probably random, fluctuations in the marked : unmarked ratio in any day's records. Consequently, the estimates of the flying population vary substantially from day to day. Rough estimates of the total adult population size can be computed for each sex in every year, and these are given in table 3 .

TABLE 3

Estimated populations of fyying adult Maniola jurtina using Folly's method

$\begin{array}{llc} & \text { Males } & \text { Females } \\ 1971 & 606 \cdot 3 & 155 \cdot 6 \\ 1972 & 265 \cdot 4 & 391 \cdot 2 \\ 1973 & 654 \cdot 7 & 204 \cdot 5 \\ 1974 & 159 \cdot 7 & 35 \cdot 1\end{array}$




\section{(ii) Sexual differences in recapture}

We have already reported that the Jolly analysis shows that there are no differences in survival between the sexes. Because records are available for every capture of each animal, it is possible to confirm this finding using a different method, and to discover an interesting difference in behaviour between the sexes. Table 4 shows the recapture rates of male and female $M$. jurtina, both later on the day that they were marked, and also on subsequent dates, for each year.

TABLE 4

The recapture rate of male and female Maniola jurtina both on the day of marking, and subsequently. Same day retrap data were not collected in 1970

$\begin{array}{lccccc}\text { 1970 Male } & \begin{array}{c}\text { Number } \\ \text { marked }\end{array} & \begin{array}{c}\text { Recaptured on } \\ \text { the same day }\end{array} & \% & \begin{array}{c}\text { Recaptured } \\ \text { subsequently }\end{array} & \% \\ \text { 1970 Female } & 217 & - & - & 117 & 53 \cdot 9 \\ \text { 1971 Male } & 135 & - & - & 47 & 34 \cdot 8 \\ \text { 1971 Female } & 128 & 17 & 13 \cdot 3 & 42 & 32 \cdot 8 \\ \text { 1972 Male } & 73 & 10 & 13 \cdot 6 & 24 & 32 \cdot 8 \\ \text { 1972 Female } & 188 & 44 & 23 \cdot 4 & 88 & 46 \cdot 8 \\ \text { 1973 Male } & 123 & 10 & 8 \cdot 1 & 33 & 26 \cdot 8 \\ \text { 1973 Female } & 214 & 33 & 15 \cdot 4 & 81 & 37 \cdot 9 \\ \text { 1974 Male } & 105 & 5 & 4 \cdot 8 & 27 & 25 \cdot 7 \\ \text { 1974 Female } & 60 & 13 & 21 \cdot 7 & 16 & 26 \cdot 7 \\ & 34 & 3 & 8 \cdot 8 & 8 & 23 \cdot 5\end{array}$

Considering first the recaptures subsequent to the date of marking, there are statistically significant differences in retrap rate from year to year $\left(\chi_{4}^{2}=22 \cdot 5\right)$. These presumably reflect differences in sampling efforts and are unlikely to be of major biological significance. There is, however, a clear and highly significant difference in recapture rate between the sexes $\left(\chi_{1}^{2}=21 \cdot 2\right)$, males being recaptured more often. This difference is consistent between years $\left(\chi_{4}^{2}=5 \cdot 4\right)$, and could have several causes. First, differential mortality could occur as the result of our marking and handling the animals. Second, there could be real differences in the survival of the two sexes that are independent of our activities. Third, there could be differences in the behaviour of the two sexes that result in a higher recapture of the males. This could take one or more of a series of forms. Males could fly less strongly, or for longer periods of the day. Alternatively, females could be more prone to emigrate out of the study area, and be less available for recapture for this reason.

Separating these alternatives is difficult. However, the result of a population cage experiment will be reported elsewhere, showing inter alia that there is no difference in the survival of male and female $M$. jurtina stemming from their being caught, handled and marked. The remaining alternatives can be disentangled by analysing recaptures later on the day of marking. It is improbable that differences in emigration or mortality are sufficiently marked to be manifest over a period as short as the 2 or 3 hours that a visit usually lasted. On the other hand, if males fly less strongly, or females fly less often, the male should be recaptured more often later on the day of marking, just as they are on subsequent days. 
In 1970, we did not keep a record of captures later on the day of marking, so we can only analyse the data over 4 years. These are present in table 4 , and show a significantly higher recapture rate among the males $\left(\chi_{1}^{2}=17 \cdot 0\right)$, with no heterogeneity between years $\left(\chi_{3}^{2}=5 \cdot 6\right)$. It seems, therefore, that male $M$. jurtina are easier to catch, but the reasons for this cannot at present be established conclusively.

\section{(iii) Variation in spot number}

There are two ways in which we can analyse the distribution of individuals in the various spot classes through each season. First, we can record a butterfly only upon the date that it was first captured and marked. Although individuals were not necessarily caught on the date of their first appearance in the population, this will give an approximation to their date of emergence. It is thus possible to look for differences in the times of appearance of the various spot classes. Alternatively, we can record every butterfly upon every day that it was observed alive. This will give an indication of the composition of the adult population on every day observations were made.

In the event, it makes little difference which method we use. Table 6 shows the results of analysing first captures using $\chi^{2}$. The number of dates that observations were made is shown, and this coupled with four, five or six-spot classes gives a large number of degrees of freedom to the data from each year. Haldane (1939) showed that when the number of degrees of freedom exceeds $30, \chi^{2}$ is distributed approximately normally. He gave formulae for its expected value and variance that are sufficiently robust for significance to be tested using the standardised normal deviate, despite small numbers of " expecteds" in the contingency table.

Applying this test to the emergence data at Site 1 shows a pattern of remarkable uniformity. Only the male $M$. jurtina in 1973 show slight signs of heterogeneity, and this could be a statistical artefact. We may conclude that there are no obvious signs of the differential emergence of spot classes that has been reported by other workers (e.g. Dowdeswell, 1961). Variation in spot number of all animals recorded on each date show a similar uniformity, except for females in 1974. Again we can detect no signs of consistent heterogeneity that might reflect biologically important phenomena.

On the strength of these results, we have felt justified in pooling the emerging butterflies at Sites 1 and 2 in each of the years 1970 to 1974 . The number of animals recorded at Site 4 is too small for analysis, and so this population has been excluded. The data from the two sites over 5 years are shown in table 5 . The analysis of these data is a little tricky because the numbers recorded at Site 2 are rather small, and quite a few cells contain fewer than five individuals. However, the males can be pooled into three groups, as less than two spots, two spots and more than two spots. They can then be analysed by partitioning $\chi^{2}$ using GLIM (Nelder, 1975). There is then no evidence of differences in spot number between the sites. Similarly, females can be pooled into unspotted, one-spotted, and more than onespotted. Again there is no difference in spot number between the two sites.

There are, however, differences between years. Table 7 lists the frequency of various spot classes in the two sexes at Site 1 over the 5 years. Considering the males first, there is no sign of variation in low-spotted individuals. However, two-spotted males decreased noticeably over the

$$
42 / \mathrm{I}-\mathrm{G}
$$


TABLE 5

Emigration of M. jurtina from Site 1. Butterflies were recorded as being recaptured on a subsequent date inside or outside the primary study area. The data from 1971 to 1974 has been pooled

$\begin{array}{lccc}\quad \text { Sex } & \text { Spots } & \text { Outside } & \text { Inside } \\ \text { Male } & <2 & 0 & 22 \\ \text { Male } & 2 & 6 & 143 \\ \text { Male } & >2 & 1 & 62 \\ \text { All males } & - & 7 & 227 \\ & & & \\ \text { Female } & 0 & 1 & 38 \\ \text { Female } & >0 & 9 & 54 \\ \text { All females } & - & 10 & 92\end{array}$

TABLE 6

The percentage spot composition of the populations of M. jurtina at Sites 1 and 2 during the five seasons 1970-74

\begin{tabular}{|c|c|c|c|c|c|c|}
\hline & & & & & & \\
\hline & & & Numbe & of spot & & \\
\hline & Year & $0 / 1$ & 2 & 3 & $4 / 5$ & size \\
\hline Site 1 & 1970 & $8 \cdot 3$ & $69 \cdot 1$ & $15 \cdot 2$ & $7 \cdot 4$ & 217 \\
\hline & 1971 & $8 \cdot 6$ & $67 \cdot 2$ & $18 \cdot 0$ & $6 \cdot 3$ & 128 \\
\hline & 1972 & 5.9 & $68 \cdot 6$ & 17.6 & $8 \cdot 0$ & 188 \\
\hline & 1973 & $4 \cdot 1$ & $65 \cdot 0$ & 21.5 & 8.9 & 214 \\
\hline & 1974 & $8 \cdot 3$ & $56 \cdot 7$ & $25 \cdot 0$ & $10 \cdot 0$ & 60 \\
\hline Site 2 & 1970 & $8 \cdot 2$ & $67 \cdot 2$ & $18 \cdot 0$ & 6.6 & 122 \\
\hline & 1971 & 0 & 77.5 & 17.5 & $5 \cdot 0$ & 40 \\
\hline & 1972 & $8 \cdot 7$ & $78 \cdot 3$ & $8 \cdot 7$ & $4 \cdot 3$ & 23 \\
\hline & 1973 & 7.9 & $60 \cdot 6$ & $21 \cdot 0$ & $10 \cdot 5$ & 38 \\
\hline & 1974 & $21 \cdot 4$ & $50 \cdot 0$ & $21 \cdot 4$ & $7 \cdot 2$ & 28 \\
\hline & & & & ales & & \\
\hline & & & Numb & of spo & & \\
\hline & Year & 0 & 1 & 2 & $3 / 4$ & size \\
\hline Site 1 & 1970 & $62 \cdot 2$ & $11 \cdot 1$ & $18 \cdot 5$ & $8 \cdot 1$ & 135 \\
\hline & 1971 & $42 \cdot 5$ & 27.4 & 20.5 & $9 \cdot 6$ & 73 \\
\hline & 1972 & $35 \cdot 4$ & $29 \cdot 2$ & $27 \cdot 4$ & $8 \cdot 0$ & 113 \\
\hline & 1973 & $41 \cdot 0$ & $34 \cdot 3$ & $18 \cdot 1$ & $6 \cdot 7$ & 105 \\
\hline & 1974 & $52 \cdot 9$ & $29 \cdot 4$ & $14 \cdot 7$ & $2 \cdot 9$ & 34 \\
\hline Site 2 & 1970 & $69 \cdot 5$ & $15 \cdot 3$ & 11.9 & $3 \cdot 4$ & 59 \\
\hline & 1971 & $44 \cdot 4$ & $22 \cdot 2$ & $29 \cdot 6$ & 3.7 & 27 \\
\hline & 1972 & $33 \cdot 3$ & $27 \cdot 8$ & 27.8 & $11 \cdot 1$ & 18 \\
\hline & 1973 & 42.9 & $28 \cdot 6$ & $25 \cdot 0$ & 3.6 & 28 \\
\hline & 1974 & 60.0 & $20 \cdot 0$ & 11.4 & $8 \cdot 6$ & 35 \\
\hline
\end{tabular}

5 years $(r=-0.841, \mathrm{P}=0.07)$, this decline being compensated by increases in both three-spotted and over-three-spotted individuals $(r=+0.954$, $\mathbf{P}=0.02$, and $r=+0.873, \mathbf{P}=0.05$, respectively). The females, on the other hand, show no consistent trends in frequency in any spot category. There are still differences between years, however. In 1970 the population 
consisted of over 60 per cent unspotted individuals. This frequency dropped significantly in 1970 and remained at the lower level thereafter. Partitioning of the $\chi^{2}$, again using GLIM, shows indeed that the later 4 years are homogeneous, and significantly different from 1970. The composition in 1970 approximates to the "second-order" variation observed and reported by Ford and his colleagues-being intermediate between the "Cornish" and "English" stabilisations (Ford, 1975). Within the "spotted" category, there is some evidence of an increase in the frequency of onespotted butterflies; while this is not formally significant $(r=+0.776$, $\mathbf{P}=0 \cdot 10)$, it does, however, mirror the regular changes observed among males.

\section{(iv) Survival of the spot classes}

We can compare the survival and catchability of the various spot categories of $M$. jurtina in precisely the same way as we did with the sexes, by analysing the frequency of recapture. Table 7 shows the number of butterflies recaptured on the same day and subsequently at Site 1 in all 5 years. Again, the data for 1970 are incomplete since "same day" recaptures were not recorded; however, the remaining 4 years show no evidence of heterogeneity either in males $\left(\chi_{6}^{2}=4 \cdot 2\right)$ or females $\left(\chi_{3}^{2}=3 \cdot 9\right)$. Nor is there any evidence of difference in catchability of the spot classes (male $\chi_{2}^{2}=1 \cdot 6$; female $\chi_{1}^{2}=0.4$ ), so we can infer that their behaviour is similar.

There are, however, strong differences in the recapture rates on subsequent dates in both sexes. Considering the females first, the 5 years are not homogeneous $\left(\chi_{4}^{2}=10 \cdot 5\right)$, for the recapture frequency of unspotted females declines consistently over the five seasons, while that for spotted rises. Either of these alone could be due to a changing pattern of sampling: a reduction

TABLE 7

The percentage recapture of different spot classes of Maniola jurtina. I refers to recapture later on the day of marking (not recorded in 1970). II refers to recaptures on a subsequent date. The total numbers of butterflies captured are shown in parenthesis. III shows the relative recapture rate of different spot classes on subsequent dates (for further details, see text)

\begin{tabular}{|c|c|c|c|c|c|c|}
\hline & Spot number & 1970 & 1971 & 1972 & 1973 & 1974 \\
\hline I & $\begin{array}{l}\text { Male <2 } \\
\text { Male } 2 \\
\text { Male >2 }\end{array}$ & - & $\begin{array}{r}9 \cdot 1(11) \\
15 \cdot 1(86) \\
9 \cdot 7(31)\end{array}$ & $\begin{array}{rr}9 \cdot 1 & (11) \\
24 \cdot 0 & (129) \\
25 \cdot 0 \quad(48)\end{array}$ & $\begin{array}{l}20 \cdot 0 \quad(10) \\
14 \cdot 4 \quad(139) \\
16 \cdot 9 \quad(65)\end{array}$ & $\begin{array}{cc}0 & (5) \\
26 \cdot 5 & (34) \\
19 \cdot 0 & (21)\end{array}$ \\
\hline & $\begin{array}{l}\text { Female } 0 \\
\text { Female }>0\end{array}$ & - & $\begin{array}{l}16 \cdot 1(31) \\
11.9(42)\end{array}$ & $\begin{array}{ll}7 \cdot 5 & (40) \\
9 \cdot 8 & (73)\end{array}$ & $\begin{array}{ll}9.3 & (43) \\
1.6 & (62)\end{array}$ & $\begin{array}{r}5.6(18) \\
12.5(16)\end{array}$ \\
\hline II & $\begin{array}{l}\text { Male }<2 \\
\text { Male } 2 \\
\text { Male }>2\end{array}$ & $\begin{array}{l}16 \cdot 7 \quad(18) \\
61 \cdot 3(150) \\
44 \cdot 9 \quad(49)\end{array}$ & $\begin{array}{l}81 \cdot 8(11) \\
30 \cdot 2(86) \\
22 \cdot 6(31)\end{array}$ & $\begin{array}{l}54 \cdot 5 \quad(11) \\
45 \cdot 7(129) \\
47 \cdot 9 \quad(48)\end{array}$ & $\begin{array}{l}50 \cdot 0 \quad(10) \\
36 \cdot 7 \quad(139) \\
38 \cdot 5 \quad(65)\end{array}$ & $\begin{array}{l}40 \cdot 0 \quad(5) \\
20 \cdot 6(34) \\
33 \cdot 3(21)\end{array}$ \\
\hline & $\begin{array}{l}\text { Female } 0 \\
\text { Female }>0\end{array}$ & $\begin{array}{ll}46 \cdot 4 & (84) \\
15 \cdot 7 & (51)\end{array}$ & $\begin{array}{l}38.7(31) \\
28.6(42)\end{array}$ & $\begin{array}{ll}30 \cdot 0 & (40) \\
25 \cdot 3 & (73)\end{array}$ & $\begin{array}{ll}25 \cdot 6 & (43) \\
25 \cdot 8 & (62)\end{array}$ & $\begin{array}{l}16 \cdot 7(18) \\
31 \cdot 3(16)\end{array}$ \\
\hline & $\begin{array}{l}\text { Male }<2 \\
\text { rela tive to } 2 \\
\text { Male }>2 \\
\text { relative to } 2\end{array}$ & $0 \cdot 272$ & $2 \cdot 709$ & $1 \cdot 193$ & $1 \cdot 362$ & $1 \cdot 942$ \\
\hline & $\begin{array}{l}\text { Female }>0 \\
\quad \text { relative to } 0\end{array}$ & 0.338 & 0.739 & 0.843 & $1 \cdot 008$ & 1.874 \\
\hline
\end{tabular}


in effort would result in a decline in recapture rate. However, both cannot, and the difference must reflect changes in survival. It is perhaps biologically more realistic to express the figures as "relative" survival rates: dividing one by the other, as at the bottom of table 7 , removes the effects due to sampling intensity. There is then a clear indication that the survival of spotted females increases over the 5 years $(r=+0.931, \mathrm{P}=0.02)$.

Turning to the males, there are also differences in the recapture rate between the spot classes. Once again, we can control for sampling by expressing all recapture rates relative to a standard-in this case the commonest, two-spotted category. The relative recapture rates are shown at the bottom of table 7. The values for low-spotted males show marked fluctuations, being particularly low in 1971. Overall, however, this class survives better than two-spotteds in the later years. The relative survival of higher-spotted males shows a progressive increase over the 5 years which is quite significant $(r=+0.914, \mathrm{P}=0.03)$.

\section{(v) Emigration}

An alternative cause of the differences in the probability of recapture of the various spot categories might be differential dispersal. If a butterfly leaves the study area it is no longer available for recapture. We do not have data for 1970, but in subsequent years we have records of $M$. jurtina that were marked at Site 1 and recaptured at one of Sites 2 and 4 . These animals are recorded in table 5. There is no evidence of differential emigration of the spot classes among males or females $(P>0.5$ and $P=0.08$, Fisher's exact test). The difference between the sexes, however, attains formal significance $\left(\chi_{(1)}^{2}=5 \cdot 5\right)$, with females showing greater powers of dispersion.

\section{(vi) Variation in size}

Adults that were unworn when caught during 1972, 1973 and 1974 were measured on marking. The results of analysing the relationship between size and sex, year, spot number and date are shown in table 8. There is

TABle 8

Analysis of variance of size of adult Maniola jurtina in the population at Site 1 in the Wyre Forest

$\begin{array}{lrrrrr}\text { Component } & \text { SS } & \text { DF } & \text { MSQ } & \text { F } & \text { P } \\ \text { Sex } & 722 \cdot 8 & 1 & 722.8 & 687 \cdot 1 & <0.001 \\ \text { Year } & 147.6 & 2 & 147.6 & 140.3 & \text { n.s. } \\ \text { Date } & 8 \cdot 3 & 1 & 8.3 & 7.9 & <0.01 \\ \text { Spots } & 0.7 & 1 & 0.7 & 0.7 & \text { n.s. } \\ \text { Year-sex } & 4 \cdot 2 & 1 & 4 \cdot 2 & 4.0 & <0.05 \\ \text { Year-date } & 4.9 & 1 & 4.9 & 4.7 & <0.05 \\ \text { Other interactions } & 15 \cdot 3 & 9 & 1.7 & 1.6 & \text { n.s. } \\ \text { Residual } & 672 \cdot 2 & 639 & 1 \cdot 1 & - & -\end{array}$

clear evidence of a difference with respect to sex, the females being appreciably larger. There is no evidence of difference in size between spot classes, but there are significant differences between years. There is no consistency in these, however, for in some years males are larger but females are smaller than in other years, and vice versa. Since the size of an adult butterfly is 
determined during larval and pupal life, this might reflect a difference in the pre-adult ecology of the two sexes. There is also evidence of a change in the size of adults with date of emergence: as a rule, later emerging individuals are smaller.

\section{Discussion}

The population of $M$. jurtina that we have principally studied inhabits a strip of rank grass adjacent to a road, and is entirely surrounded by trees. It is well isolated from all other populations, apart from that in Site 2, and seems to be fairly small. We never estimated the number of flying adults to exceed 1000, although the number of larvae was probably many times that figure.

The overall survival rates are relatively uniform, varying neither with year nor sex. There is, however, a consistent decline in daily survival through the flying season. This implies that late-eclosing individuals live for an appreciably shorter period than those that emerge earlier. For example, butterflies emerging in early July have a daily survival probability of 0.854 , which means that 50 per cent of them will survive 4.4 days. Individuals that appear 6 weeks later in mid-August have a survival rate reduced to 0.729 , corresponding to an expectation of life of only 2.2 days. If mating and egglaying takes place uniformly through the life of an adult $M$. jurtina, these figures indicate that individuals appearing earlier might have a fitness twice as high as those that emerge later in the season.

Such a difference could have significant effects upon the spot distribution of a population of $M$. jurtina if the various classes emerge at different times of the season. We have no evidence of gross differences in emergence pattern, although these have been reported by Dowdeswell (1961) who found that higher-spotted individuals appeared at the beginning of the emergence. Indeed, when we examine our data more closely, it transpires that in all 4 years there were marginally more unspotted females in the first quarter of the butterflies to be caught than the last. The result is not statistically significant $(\mathrm{P}>0 \cdot 1)$, and does not appear among the males. A possible cause of Dowdeswell's results is the loss of spots by butterflies during their lifetime. We have recorded the number of spots on each butterfly on every date that it was captured during 1973 and 1974, and three out of 259 spotted males and four of 78 females showed a loss of one or more spots-presumably by abrasion. Such a phenomenon might cause an apparent decrease in the spot number of the population with time. However, spot-loss in our population is very slight, and is unlikely to have any major effect. It would seem to be safe to conclude that there is no variation in the emergence pattern of the butterflies that could be influenced by the intra-seasonal variation in survival.

We also have a complex pattern of size variation in males and females from year to year, although spot number plays no part in this (table 8). There are, however, marked differences in the size of $M$. jurtina between years, and in both sexes there are occasional significant changes in size within a season (see table 9). We are at a loss to be able to account for this without recourse to special pleading. It is probable that the size of a population of butterflies may show some relationship to the climatic conditions under which the larvae were reared. Our ecological data are too limited for a realistic appraisal of this, which is currently under review; 
however, it has a few interesting implications. For example, differences in size of the females might reflect differential fitness, if larger females lay more eggs. Again, however, the lack of variation in spot number with date is unlikely to make intra-seasonal size variation a factor that influences the population genetics of spotting in $M$. jurtina.

We have found evidence of a difference in the flight behaviour of the two sexes. Males show a significantly higher recapture rate which seems not to be a function of differential survival. It could stem from any or all of three causes, namely a higher dispersion of the females, or weaker flight, or greater activity of the males. We have found a significantly greater level of emigration among females, and this has also been demonstrated in Pararge aegeria by Davies (1978) who found a greater distance between marking and recapture locality in that sex. However, in 4 years of the present study only 17 butterflies were found to have moved to Sites 2 and 4 out of a total of 336 marked at Site 1. This would seem to be in accord with Ford's (1975) contention that a very short distance of unsuitable habitat poses a substantial barrier to $M$. jurtina.

\section{TABLE 9}

The regression formulae of size in $\mathrm{mm}$ against the number of days since first emergence at Site 1 in the Wyre Forest. The probability that the regression coefficient is zero is also shown

$\begin{array}{lll}1972 \text { Male } & \text { Size }=23.08-0.047 \text { date } & P=0.02 \\ 1972 \text { Female } & \text { Size }=24.66-0.025 \text { date } & P=0.20 \\ & & \\ 1973 \text { Male } & \text { Size }=21.57+0.024 \text { date } & P=0.05 \\ 1973 \text { Female } & \text { Size }=23.40+0.027 \text { date } & P=0.03 \\ & & \\ 1974 \text { Male } & \text { Size }=20.67+0.054 \text { date } & P=0.07 \\ \text { 1974 Female } & \text { Size }=23.03+0.042 \text { date } & P=0.25\end{array}$

The alternatives of a weaker or more prolonged flight of the males has less supporting evidence. The former would be at variance with Ford's observation that " the males in particular can be difficult to catch", although, Dowdeswell (pers. comm.) and our own observations suggest that this may not always be the case. The latter might be supported by Wiklund's observations upon Leptidea sinapis. He found (1977) that males spent much of the day in flight, whereas females flew rather little. A study of the behaviour of $M$. jurtina in the field is currently under analysis, and this will cast further light upon this situation.

Over the 5 years of the study, the recapture rate of three and fourspotted males increased relative to two-spotteds. This trend could stem either from differences in survival or behaviour, such as dispersal from the natal area or differential flight behaviour. The limited data pertaining to emigration in males suggest there to be no differential effects between spot classes. Furthermore, the fact that the probability of recapture later on the day of capture is unrelated to phenotype argues that the longer term effect reflects differential survival of the spot classes. A similar regular increase in the recapture rate of spotted females relative to unspotteds can also be attributed to their superior survival in later years. 
The frequency of two-, three- and four-spotted males changes in parallel with these fluctuating survival rates. Two-spotteds steadily decline in frequency, while the other two increase in their stead. It is tempting to postulate causes and effects. Gharacters that show a high heritability can be particularly responsive to selection. High-spotted males survive better than two-spotteds, and increase in frequency relative to them as well. It could be argued that this increase stems from an enhanced reproductive performance, resulting from their longer life.

Females also show differential survival, with spotteds again apparently living longer in the later years of the study. If females lay eggs continuously through their adult life, this should also produce a differential fitness between the phenotypes acting against unspotteds. There is no evidence of a decrease in the frequency of unspotteds, however, so the relationship cannot be completely straightforward.

Indeed, when we turn to the evidence that spotting in $M$. jurtina has any genetic basis at all, we have cause for concern. The only published estimates of heritability are those of McWhirter (1969). His data are rather limited, however, as the number of broods upon which they are based is only four, of which two produced less than 10 offspring of each sex. Since the species shows differences in spot number between males and females, the sexes must be considered separately. Not only are the number of offspring limited in one half of the crosses, but the parents of the two reasonably large broods were respectively five-spot male $x$ three-spot female and zero-spot male $\times$ five-spot female. Three of these are among the rarest and least known $M$. jurtina phenotypes, and estimates of heritability based upon data such as these must be viewed with caution. It is probable that were Maniola a more tractable laboratory animal, data as weak as these would be inadmissable.

It is a moot point whether difficulties in rearing the beast in controlled conditions should allow a lower standard of rigour in the assessment of the data. However, the fact remains that this is the only information available, and it suggests the character of spotting to have a much lower heritability in the males than the females. Our present results are at variance with these estimates, for the males (with a low heritability) seem to be responding to the differential survival, whereas the females (with a higher heritability) are not. In a future publication, we will describe some further results both from an analysis of the behaviour of the species, and from later years of the population study, that will suggest an alternative explanation for the character of spotting and its control in Maniola jurtina. In the meantime, we conclude that it is imperative to obtain more information concerning the inheritance of this vexed character. Then it will be possible to simulate the behaviour of individual populations. In particular, it will be possible to analyse the results from the wildly fluctuating populations in south-western Britain, to determine the magnitude of any selective forces involved in adjusting their phenotypic composition.

Acknowledgments. - It is a pleasure to record our gratitude to the landowners who have allowed us access to their property during this research. During the preparation of the paper we have benefited greatly from discussions with Professors Bryan Clarke and W. $H$. Dowdeswell, and Mr John Muggleton. Professors Clarke and Dowdeswell and Mr Paul Brakefield read an earlier manuscript. Their constructive criticism has improved it greatly, as has an anonymous referee. D. T. P. acknowledges support from S.R.C. Research Grant number B/RG 59997. 


\section{REFERENCES}

DAvies, N. B. 1978. Territorial defence in the speckled wood butterfly (Pararge aegeria): The resident always wins. Anim. Behav., 26, 138-147.

DOWDESWELL, W. H. 1961. Experimental studies on natural selection in the butterfly Maniola jurtina. Heredity, 16, 39-52.

DOWDESWELL, W. H., FORD, E. B., AND MCWHIRTER, K. G. 1957. Further studies on isolation in the butterfly Maniola jurtina L. Heredity, 11, 51-65.

FISHER, R. A., AND FORD, E. B. 1947. The spread of a gene in natural conditions in a colony of the moth Panaxia dominula L. Heredity, 1, 147-174.

FORD, E. B. 1975. Ecological Genetics. Chapman and Hall, London.

HALDANE, J. B. s. 1939. The mean and variance of $\chi^{2}$ when used as a test of homogeneity, when expectations are small. Biometrika, 31, 346-355.

JOLLY, G. M. 1963. Estimates of population parameters from multiple recapture data with both death and dilution-deterministic model. Biometrika, 50, 113-128.

JOLLY, G. M. 1965. Explicit estimates from capture-recapture data with both death and immigration-stochastic model. Biometrika, 52, 225-247.

MCWHIRTER, K. G. 1969. Heritability of spot-number in Scillonian strains of the Meadow Brown butterfly (Maniola jurtina, L.). Heredity, 24, 314-318.

MCWHIRTER, K. G., AND CREED, E. R. 1971. Analysis of spot placing in the Meadow Brown butterfly, Maniola jurtina. In Ecological Genetics and Evolution, ed. E. R. Creed. Blackwell, Oxford.

NELDER, J. A. 1975. General Linear Interactive Modelling. Release 2. National Algorithms Group, Oxford.

WIKLUND, c. 1977. Oviposition, feeding and spatial separation of breeding and foraging habitats in a population of Leptidea sinapis, (Lepidoptera). Oikos, 28, 56-88. 